\title{
UM ENFOQUE TERMODINÂMICO PARA O ESTUDO DO COMPORTAMENTO DE REFRATÁRIOS MGO-C NA LINHA DE ESCÓRIA DE PANELAS PARA AÇO LÍQUIDO*
}

\author{
Maísa Villela Freire ${ }^{1}$ \\ Jorge Juarez Trujillo ${ }^{2}$ \\ Sérgio Luiz Cabral da Silva ${ }^{3}$ \\ André Luiz Vasconcellos da Costa e Silva
}

Resumo

Refratários MgO-C encontram-se entre os mais adequados para o uso na linha de escória de panelas para aço líquido. Seu comportamento, nesta aplicação, depende de fatores termodinâmicos e cinéticos. Métodos de cálculo termodinâmico para avaliar o potencial de degradação de refratários MgO-C por escórias e pela atmosfera são revistos brevemente. Tais métodos envolvem, em geral, premissas importantes sobre a quantidade de materiais envolvidos. Para avaliar um método mais simples, foram escolhidos dois tijolos MgO-C e duas escórias típicas do processo da CSN. Estes tijolos e escórias foram caraterizados, neste trabalho. O método apresentado consiste na realização de cálculos de equilíbrio em que a principal variável é a fração de escória em uma mistura hipotética com o refratário. Para a composição do refratário foram empregadas (a) composição média e (b) composição da matriz do tijolo. Os resultados indicam que é possível realizar previsões iniciais quanto à reatividade do refratário e determinada escória de forma simples. Os cálculos, evidentemente, não substituem testes cinéticos e testes em escala industrial, em vista da complexidade dos sistemas em questão.

Palavras-chave: Refratários; Escória; MgO-C, Panelas de aço.

\section{A THERMODYNAMIC APPROACH TO THE EVALUATION OF THE BEHAVIOR OF MGO-C REFRACTORIES IN THE SLAG LINE OF STEEL LADLES}

\section{Abstract}

$\mathrm{MgO}-\mathrm{C}$ refractories are some of the most adequate for the use in the slag line of steel ladles. The behavior of these refractories in this application depend both on thermodynamic and kinetic aspects. The most common thermodynamic calculation approaches used to study this interaction are briefly reviewed. These methods depend, in general, on important assumptions about the amount of materials interacting. In order to evaluate a simpler method, two MgO-C bricks and two slags typical of CSN process were used. These bricks and slags were characterized in the present work. The thermodynamic method in question involves equilibrium calculations in which the main variable is the fraction of slag in a hypothetical mixture with the refractory. For the refractory composition, two different values were considered: the average composition and the matrix composition. The results indicate that it is possible to make preliminary predictions concerning the refractory reactivity when exposed to a given slag. These calculations, evidently, will not substitute kinetic and industrial tests, in view of the complexity of the systems in question.

Keywords: Refractories; Slag; MgO-C; Steel ladle.

1 Estudante, Engenharia Metalúrgica, Universidade Federal Fluminense, Volta Redonda, RJ,Brasil.

2 Engenheiro Industrial, Mestre em Engenharia Mecânica, Professor, EEIMVR, Universidade Federal Fluminense, Volta Redonda, RJ, Brasil.

3 Engenheiro, PhD, Pesquisador, Magnesita, Contagem, MG, Brasil.

4 Engenheiro Metalurgista, MASc, PhD, Professor, EEIMVR, Universidade Federal Fluminense, Volta Redonda,RJ, Brasil.. 


\section{INTRODUÇÃO}

Além de transportar o aço vazado dos conversores até o lingotamento contínuo, a panela de aço é um importante reator durante os processos de refino secundário do aço. Os processos de siderurgia têm a característica notável de que o revestimento dos reatores participa e é consumido durante os processos.

O aço é vazado dos processos primários (conversor e forno elétrico) em panelas revestidas de material refratário. A seleção do tipo de material refratário empregado é, em geral, realizada conforme o tipo de solicitação de cada região do equipamento. A linha de escória é normalmente sujeita a solicitações rigorosas nestes equipamentos, frequentemente definindo a vida das panelas [1]. De forma geral, para esta aplicação, são exigidos materiais quimicamente compatíveis com a escória (elevada resistência à corrosão química), com elevada refratariedade, baixa porosidade aparente, baixa permeabilidade, boa resistência ao choque térmico. Em vista da sua compatibilidade com escórias básicas e resistência à hidratação, o MgO é uma escolha comum. Diversos mecanismos, que serão discutidos brevemente adiante, fazem com que adições de carbono sejam úteis para reduzir a reação do refratário com a escória. Quando carbono é empregado (refratários $\mathrm{MgO}-\mathrm{C}$ ), a resistência à oxidação pode se tornar uma propriedade importante [2] e a oxidação se torna um mecanismo de desgaste relevante [3]. Tijolos de MgO-C (MagnésiaCarbono), compostos majoritariamente por magnésia sinterizada ou eletrofundida, são materiais que tem apresentado bom desempenho em aplicações em panelas de aço devido ao seu alto ponto de fusão e sua elevada resistência química em ambiente básico [4]. As adições de carbono visam aproveitar (a) sua baixa molhabilidade pela escória (b) potenciais reações entre o $\mathrm{MgO}$ e o carbono formando uma camada densa de $\mathrm{MgO}$ na face do refratário exposta à escória e mais altas temperaturas [5] e, eventualmente, prevenir reações entre os diversos óxidos presentes no refratário, idealmente retardando o aparecimento de fase líquida.

A linha de escória é degradada principalmente por processos de corrosão decorrentes da interação do refratário com a escória. Estes processos envolvem, naturalmente, uma força motriz termodinâmica e ocorrem a velocidades definidas pelas características dos materiais envolvidos e do processo de refino em questão. $O$ conhecimento das possíveis interações termodinâmicas é fundamental como base para uma análise inicial da resistência de um refratário ao meio onde será empregado. O ataque pela escória se dá em função do desequilíbrio termodinâmico entre escória e refratário [5,6]. Este desequilíbrio pode ser estudado experimentalmente, em laboratório ou através de cálculos termodinâmicos ou combinação das duas técnicas [7]. No presente trabalho optou-se por avaliar a compatibilidade refratário-escória usando cálculos termodinâmicos. Naturalmente, os resultados dos cálculos termodinâmicos consideram apenas situações de equilíbrio, as quais são difíceis de serem alcançadas nos sistemas cerâmicos. De qualquer forma, estes resultados indicam a direção para onde o sistema tende a se deslocar e, como a força motriz dos processos de desgaste é, normalmente, a diferença de potencial químico, dá, também, indicação indireta da facilidade de dissolução do refratário na escória [8]. Assim, para completo entendimento dos mecanismos de reação e desgaste, são simultaneamente necessárias as análises termodinâmicas e microestruturais dos materiais [9]. 


\section{CALCULOS TERMODINAMICOS APLICADOS A REFRATÁRIOS MgO-C}

Diversos autores buscaram desenvolver métodos para avaliar, termodinamicamente, o comportamento que pode ser esperado dos complexos sistemas existentes nos refratários $\mathrm{MgO}-\mathrm{C}$, onde, além de óxidos, um forte redutor (o $\mathrm{C}$ ) e aditivos metálicos (para proteger o C contra a oxidação) estão presentes. A seguir são resumidas algumas das contribuições mais relevantes, ligadas a refratários $\mathrm{MgO}-\mathrm{C}$ em aciaria. Lehmann. $[10,11]$ avaliou as condições de formação da chamada camada densa de $\mathrm{MgO}$ [12] através da reação do $\mathrm{MgO}$ com o $\mathrm{C}$, transporte de vapor e reoxidação assim como interações entre escória, metal e refratários, usando um software proprietário do IRSID. Lee [5,9] realizou cálculos empregando uma massa inicial do refratário "novo" e adições de gás (rico em oxigênio) e de escória, para avaliar as mudanças estruturais que ocorrem tanto durante o aquecimento da panela como na interação do refratário com a escória. Avaliaram, também, a formação da camada densa [13]. Os resultados envolvem tanto as fases condensadas quanto a fase gasosa e, embora úteis, dependem de diversas premissas, especialmente quanto à quantidade de gás e escória adicionados ao sistema. Kasimagwa [14] estudou a estrutura de refratários de doloma, doloma-C e MgO-C usados em aciaria usando diagramas clássicos de fração de fases versus temperatura calculados com Thermo-calc [15] e banco de dados SLAG3[16]. Kasimagwa usou composições estimadas com base em observações de penetração de escória nos refratários testados. Desta forma, os resultados são relativamente dependentes da observação experimental, mas contribuíram para a compreensão dos fenômenos observados. Kasimagwa também realizou cálculos para a determinação das condições para a formação da camada densa.

\section{MATERIAIS E MÉTODOS}

\subsection{CÁLCULOS TERMODINÂMICOS}

No presente trabalho empregou-se o software Thermo-calc [15] e o banco de dados SLAG3[16]. Os cálculos foram realizados a partir da composição medida em dois tijolos usados em linha de escória (descritos no item a seguir) e em duas composições extremas do processo de aciaria de uma siderúrgica de aços planos. Para avaliar o efeito da escória foram realizados cálculo ao longo de composições químicas calculadas como uma ponderação entre o refratário e a escória, desde escória pura até refratário puro, considerando, para o refratário, duas composições diferentes, como será discutido no item 3.2. A composição média do refratário e a composição química da matriz, entre os grãos de MgO sinterizada ou eletrofundida. Neste trabalho, matriz é considerada a porção da microestrutura do material entre os grãos de magnésia eletrofundida. O termo "fases acessórias" é usado para designar eventuais fases presentes no interior dos grãos de $\mathrm{MgO}$ eletrofundida, quando estes não são mono-cristalinos.

\subsection{TIJOLOS REFRATÁRIOS}

Para a obtenção das informações sobre composição química do refratário, foram empregados tijolos de magnésia-carbono, retirados após o uso, no final da campanha, da linha de escória de duas panelas de aço da CSN. Os dois tijolos estudados têm características muito semelhantes. Tijolo refratário $A$, com magnésia eletrofundida, 
antioxidantes, resinado e curado, contendo $12,5 \%$ de carbono e o tijolo refratário "B", com magnésia eletrofundida, antioxidantes, resinado, curado, contendo $13 \%$ de carbono. As principais propriedades originais e especificadas destes tijolos são apresentadas na Tabela 1.

Tabela 1: Comparação das análises físico-químicas das amostras dos tijolos $A$ e $B$ em relação às características originais especificadas

\begin{tabular}{llcccc}
\hline & $\begin{array}{c}\text { Item } \\
\text { analisado }\end{array}$ & $\begin{array}{c}\text { Amostra } \\
\mathrm{A}\end{array}$ & $\begin{array}{c}\text { Características } \\
\text { Originais A }\end{array}$ & $\begin{array}{c}\text { Amostra } \\
\mathrm{B}\end{array}$ & $\begin{array}{c}\text { Características } \\
\text { Originais B }\end{array}$ \\
\hline Propriedades & $\mathrm{DMA}\left(\mathrm{g} / \mathrm{cm}^{3}\right)$ & 2,94 & 2,95 & 2,96 & 2,95 \\
\cline { 2 - 6 } Físicas & $\mathrm{PA}(\%)$ & 8,99 & 11 & 7,6 & 9,6 \\
\hline Análise & $\mathrm{MgO}(\%)$ & 92,38 & 92,0 & 91,94 & 93,5 \\
química & $\mathrm{C} \mathrm{Total}(\%)$ & 12,5 & 12,5 & 11,31 & 13 \\
\hline
\end{tabular}

Para as análises do tijolo usado, foram retirados corpos de prova afastados da superfície de trabalho em contato com a escória (parte escura da Figura 1). No tijolo A, a amostra foi retirada a cerca de $40 \mathrm{~mm}$ da face de trabalho e no tijolo $B$, a $45 \mathrm{~mm}$ desta face. A amostragem foi realizada neste ponto para obter medidas de propriedades próximas as originais do tijolo, apenas afetadas pela exposição a temperaturas médias e sem oxidação significativa.

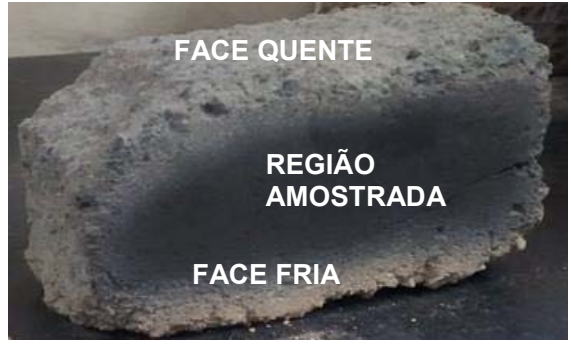

(a)

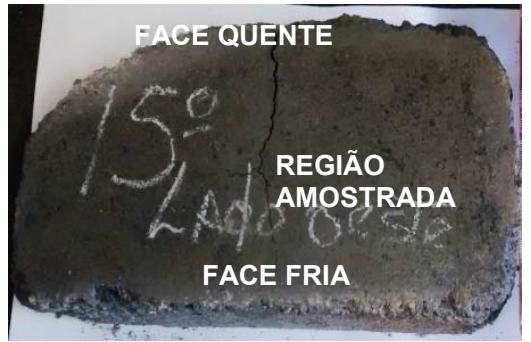

(b)

Figura 1: Amostras dos refratários utilizados no estudo (a) tijolo A e (b) tijolo B.

Para a análise química através de espectrômetro de fluorescência de raios- $X$ e a medida do carbono total, as amostras foram pulverizadas abaixo de 106 micrometros. A avaliação de fases presentes foi realizada por difratometria de Raios X. A medida de densidade de massa aparente (DMA) (NBR 6220 [17]) e da porosidade aparente (PA) (NBR 6220) foram realizadas em amostras cortadas em via úmida. Os valores das análises químicas estão na Tabela 2.

Tabela 2: Análise química por fluorescência de raios $\mathrm{X}$ das amostras refratárias

\begin{tabular}{clccccc}
\hline Tijolo & Análise Química & $\mathrm{CaO}$ & $\mathrm{FeO}$ & $\mathrm{MgO}$ & $\mathrm{SiO}_{2}$ & $\mathrm{Al}_{2} \mathrm{O}_{3}$ \\
\hline \multirow{2}{*}{$\mathrm{A}$} & Real & 1,44 & 0,31 & 92,38 & 1,00 & 4,25 \\
\cline { 2 - 7 } & Normalizada & 1,45 & 0,31 & 92,96 & 1,01 & 4,27 \\
\hline \multirow{2}{*}{$\mathrm{B}$} & Real & 1,95 & 0,29 & 91,74 & 0,83 & 4,42 \\
\cline { 2 - 7 } & Normalizada & 1,96 & 0,3 & 92,46 & 0,83 & 4,45 \\
\hline
\end{tabular}

Os dois tijolos contêm alumínio metálico $(\mathrm{Al})$ como antioxidante, o que contribui para o teor de $\mathrm{Al}_{2} \mathrm{O}_{3}$ encontrado na análise química [2]. A Figura 2 apresenta os difratogramas obtidos para os dois tijolos. 


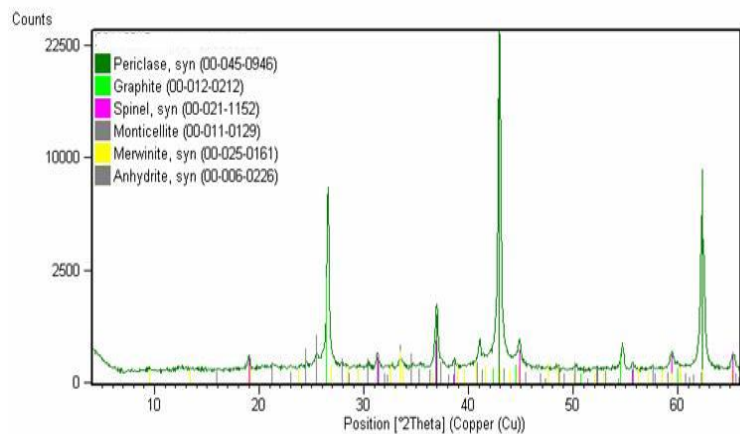

(a)

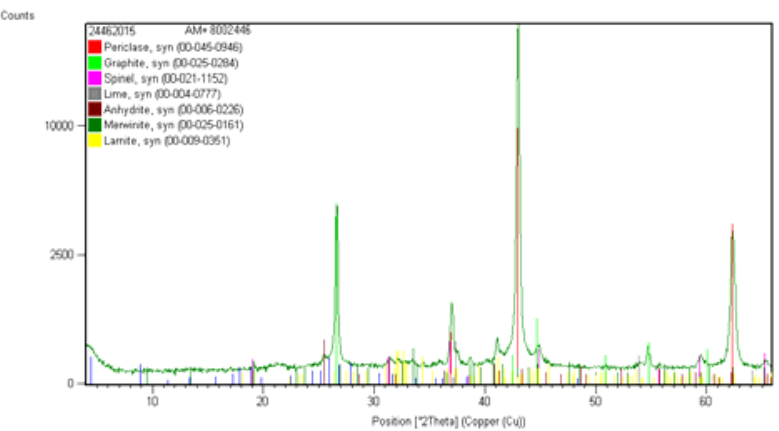

(b)

Figura 2. Difratogramas das amostras (a) tijolo A e (b) tijolo B.

A técnica de difração de raios-X (Figura 2) permitiu observar que o tijolo $A$ apresentou, como fases majoritárias o periclásio $(\mathrm{MgO})$, grafita $(\mathrm{C})$, espinélio $\left(\mathrm{MgAl}_{2} \mathrm{O}_{4}\right)$ e monticelita (CaMgSiO4). Já o tijolo $\mathrm{B}$ apresentou principalmente periclásio, grafita e espinélio. A identificação da fase mineralógica espinélio em ambos pode ser justificada pela presença do antioxidante alumínio metálico [1].

As Figuras 3 e 4 apresentam os resultados da avaliação ceramográfica dos dois tijolos.
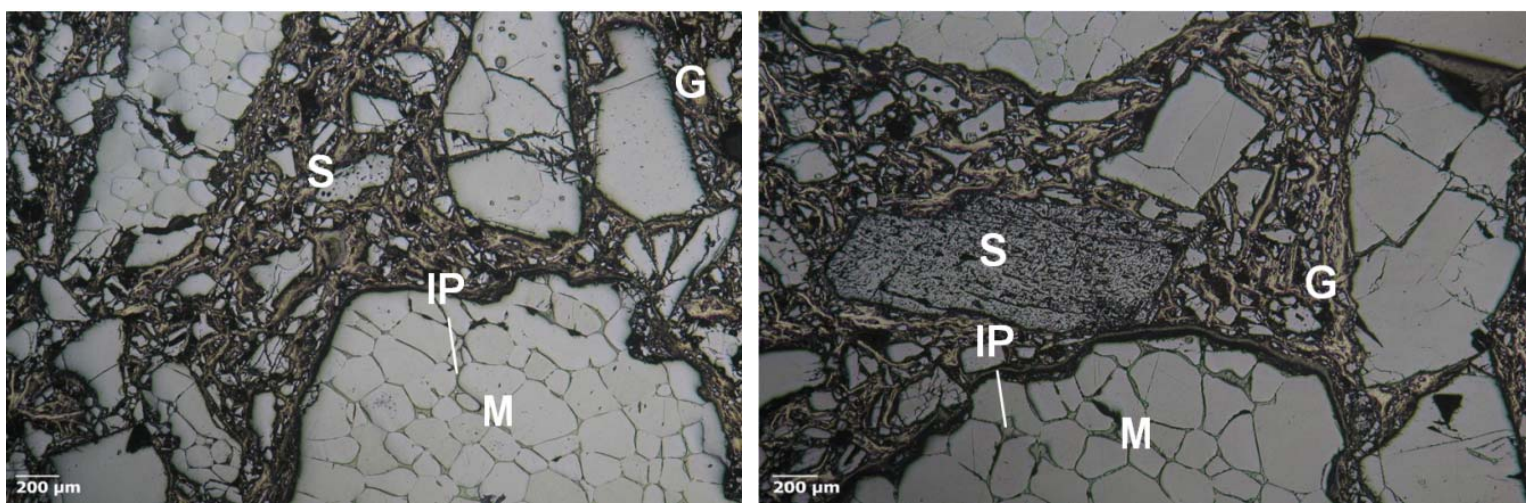

Figura 3: Micrografias do Tijolo A (x50). M: Magnésia Eletrofundida; S: Magnésia Sinterizada; G:Grafita; IP: "fases acessórias", no interior dos grandes grãos de magnésia eletrofundida.
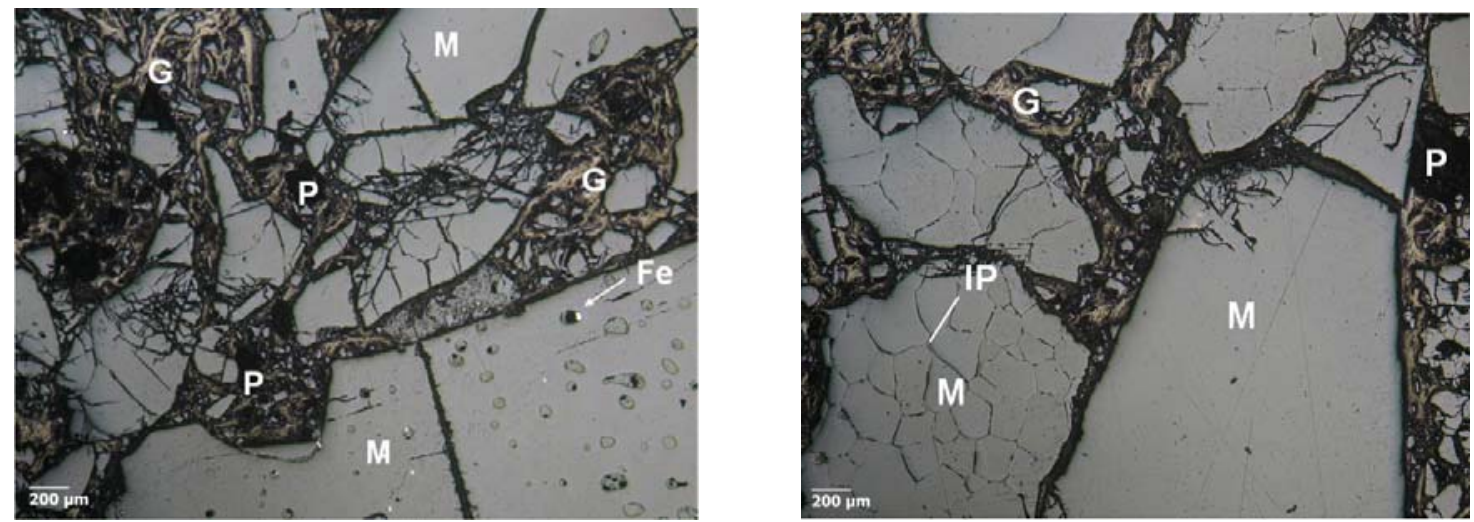

Figura 4 Micrografias do Tijolo B (x50). M: Magnésia Eletrofundida; G: Grafita; IP: "fases acessórias", no interior dos grandes grãos de magnésia eletrofundida.; P:Pó Metálico; Fe: Ferro

A microestrutura do tijolo A (Figura 3) apresentou grãos de $\mathrm{MgO}$ eletrofundidos e sinterizadados distribuídos na matriz, porém com a presença de fração considerável de grãos pequenos. As interfaces dos grãos de $\mathrm{MgO}$ são bem definidas, indicando, como esperado pelo local da amostragem, que não ocorreu ataque destes grãos. Os 
grãos eletrofundidos apresentaram a presença de impurezas entre os cristais de periclásio.

A microestrutura do tijolo B (Figura 4) apresentou a presença de grãos eletrofundidos, com baixo nível de impureza e maior tamanho dos cristais. Foi possível observar uma pequena infiltração de ferro, possivelmente ocorrida devido à amostragem ter sido realizada próxima à uma trinca central do tijolo. Nos dois casos, só foi observada grafita como fonte de carbono no refratário.

Para a realização dos cálculos termodinâmicos foram consideradas, como discutido acima, a composição média do tijolo e a composição da matriz do tijolo. A composição da matriz foi obtida da seguinte forma: Foi determinada para cada tijolo, por metalografia quantitativa por contagem de pontos [18] a fração volumétrica de magnésia eletrofundida (as "fases acessórias" presentes na magnésia eletrofundida foram consideradas como parte desta fase). Considerou-se a magnésia fundida $100 \%$ densa, tendo a densidade do $\mathrm{MgO}$. Conhecendo a densidade de massa aparente de cada tijolo, foi possível determinar a fração em massa de magnésia fundida em cada tijolo. Deduzindo-se esta fração em massa e a fração em massa de carbono da composição informada na especificação do tijolo e convertendo o $\mathrm{Fe}_{2} \mathrm{O}_{3}$ daquela composição em FeO (por ser o óxido de ferro para o potencial de oxigênio nas condições de metalurgia de panela [8]), determinou-se a fração de massa aproximada de cada óxido na "matriz" (região entre os grãos de magnésia eletrofundida), normalizada a $100 \%$. O carbono foi eliminado dos cálculos de concentração pois, em equilíbrio termodinâmico, diversas reações de redução pelo carbono são possíveis, mas, excetuando a formação da camada densa de $\mathrm{MgO}[5,12]$, que não era o interesse deste estudo, estas reações não são prováveis na utilização do refratário em questão. Este método tem a limitação de incluir, na composição da matriz, as "fases acessórias". Em uma próxima etapa estas duas composições serão determinadas, com maior exatidão, e a análise termodinâmica realizada novamente, para avaliar separadamente, o efeito da matriz e das "fases acessórias" na corrosão do refratário exposto a escória.

Os valores assim calculados para a matriz de cada refratário estão na Tabela 3.

Tabela 3: Composição das matrizes das amostras refratárias (\%).

\begin{tabular}{cccccc}
\hline Amostra & $\mathrm{CaO}$ & $\mathrm{FeO}$ & $\mathbf{M g O}$ & $\mathbf{S i O}_{2}$ & $\mathbf{A l}_{2} \mathbf{O}_{3}$ \\
\hline A & 7,46 & 1,58 & 63,76 & 5,18 & 22,02 \\
\hline B & 13,37 & 2,04 & 48,58 & 5,69 & 30,32 \\
\hline
\end{tabular}

As características ceramográficas como a oxidação superficial e as regiões reagidas serão discutidas em outro trabalho.

\subsection{ESCÓRIAS}

As escórias empregadas nos cálculos foram escórias da elaboração de aço classificado como ABNT 1006. Para representar duas escórias diferentes, ao longo do processamento na panela, foram escolhidas a escória que antecede o vazamento no Conversor LD (antes de qualquer desoxidação) e a escória após completa desoxidação com alumínio (acalmado) na Estação de Borbulhamento (EB). Amostras destas escórias foram pulverizadas abaixo de 106 micrometros, e analisadas por espectrômetro de fluorescência de raios $X$.

A tabela 4 apresenta o resultado das análises químicas das escórias mencionadas: 
Tabela 4: Análise química das escórias no processo (\%).

\begin{tabular}{lcccccc}
\hline Escórias & $\mathbf{C a O}$ & $\mathbf{F e O}$ & $\mathbf{M g O}$ & $\mathbf{M n O}$ & $\mathbf{S i O}_{2}$ & $\mathbf{A l}_{2} \mathbf{O}_{3}$ \\
\hline Conversor & 45,22 & 23,77 & 12,51 & 4,18 & 13,24 & 1,08 \\
\hline Via EB Acalmado & 40,52 & 4,06 & 9,6 & 4,8 & 8,52 & 32,5 \\
\hline
\end{tabular}

\section{CÁLCULOS TERMODINÂMICOS}

Os cálculos termodinâmicos apresentados a seguir consideraram (a) que os aditivos metálicos anti-oxidantes, eventualmente adicionados ao tijolo, já estivessem completamente oxidados, como sílica e alumina, e (b) a ausência de carbono, como já discutido.

Embora os tijolos não atinjam, necessariamente, o equilíbrio termodinâmico durante seu emprego, uma informação inicial interessante é o potencial de formação de fase líquida e das demais fases que podem ocorrer no tijolo, durante sua exposição a temperatura elevada. A Figura 5 apresenta a fração molar das fases presentes nos dois tijolos, em equilíbrio, a temperatura elevada.
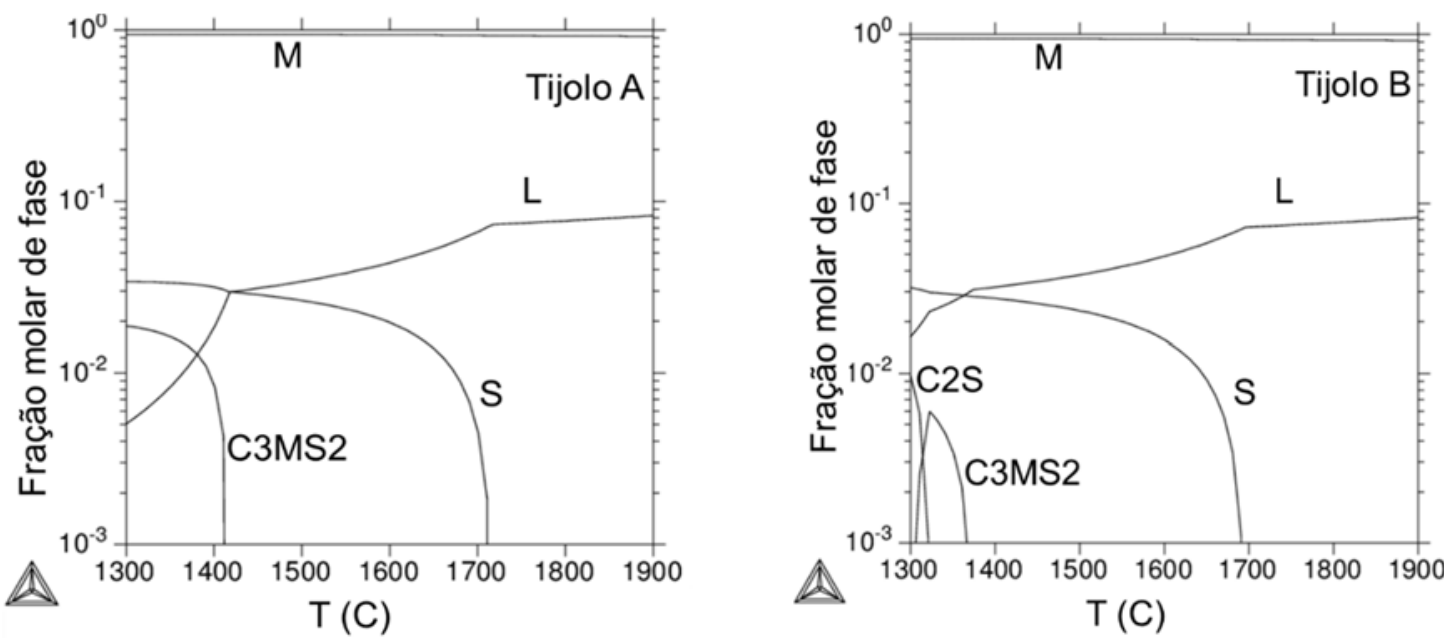

Figura 5. Fração molar de fases em equilíbrio nos tijolos $A$ e $B$, em função da temperatura. Ver texto para discussão. $\mathrm{L}=$ =líquido $\mathrm{M}=\mathrm{MgO}, \mathrm{S}=$ espinélio, $\mathrm{C} 3 \mathrm{MS} 2=3 \mathrm{CaO} . \mathrm{MgO} .2 \mathrm{SiO}_{2}, \mathrm{C} 2 \mathrm{~S}=2 \mathrm{CaO} . \mathrm{SiO}_{2}$

Além do domínio da fase $\mathrm{MgO}$ em todas as temperaturas, observa-se que os dois tijolos apresentam fração de fase líquida relativamente baixa, atingindo cerca de $10 \%$ a $1900^{\circ} \mathrm{C}$. A fração de líquido do tijolo A aumenta mais lentamente, com a temperatura, do que a do tijolo B. Embora ambos formem espinélio e C3MS2 quando expostos a temperaturas elevadas, o tijolo B pode, também, formar C2S. Neste caso, a operação contínua da panela a temperatura elevada é ainda mais importante, em vista da transformação de fase deste composto. Dentre os métodos possíveis para avaliar a interação entre o tijolo e as escórias, neste trabalho é apresentado o uso de seções isopletas em que a composição varia desde a composição da escória em estudo até a composição do tijolo em avaliação, variando-se, continuamente, a proporção destes dois materiais, expresso, nos diagramas, como "fração de refratário", variando de 0 até 1. Uma primeira análise possível é avaliar a interação entre a escória e o refratário como um todo (composição média do refratário). A Figura 6 apresenta as seções isopletas relativas às combinações dos dois tijolos com a escória do conversor. Nem todas as fases foram identificadas nas isopletas, para facilitar sua leitura. 

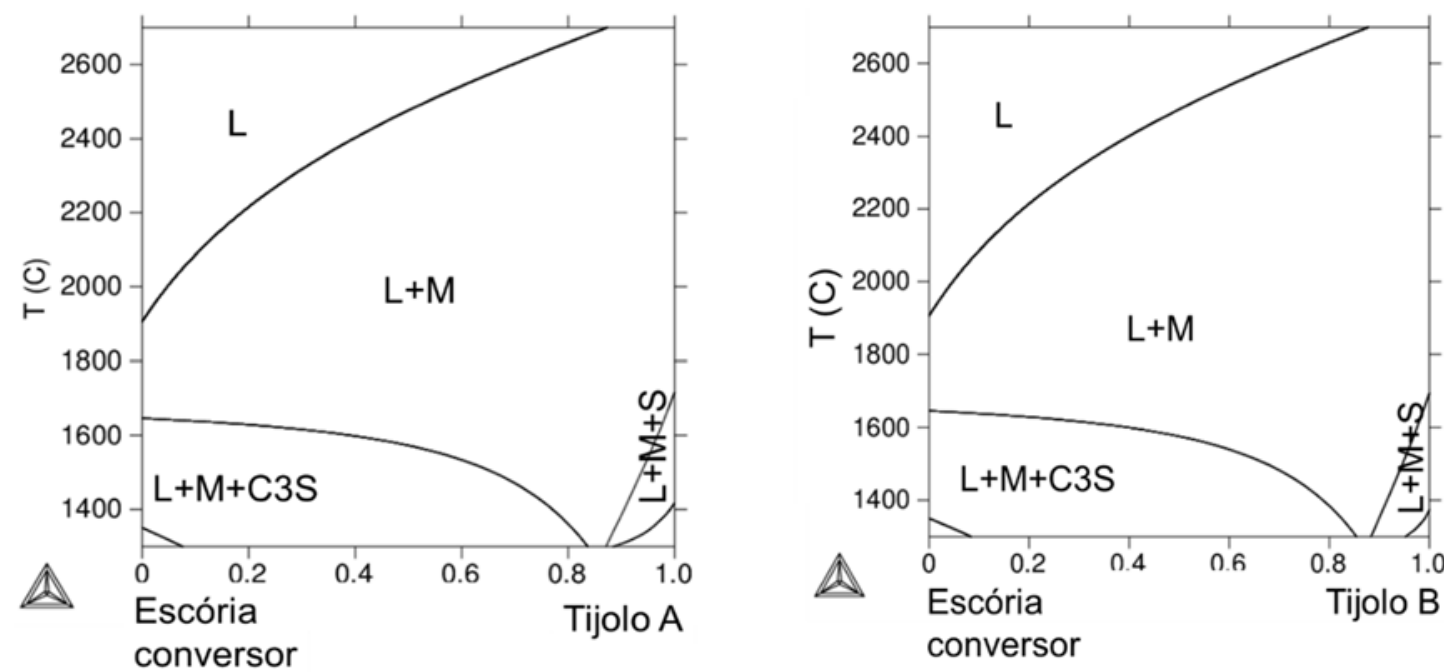

Figura 6 Isopletas entre a escória de conversor e as composições médias dos tijolos A e B. O potencial de oxigênio, nos cálculos, foi ajustado para a predominância do $\mathrm{FeO}$ dentre os óxidos de Fe. $\mathrm{L}=$ líquido $\mathrm{M}=\mathrm{MgO}, \mathrm{S}=$ espinélio, $\mathrm{C} 3 \mathrm{~S}=3 \mathrm{CaO} \cdot \mathrm{SiO}_{2}$.

Na Figura 6 observa-se que o comportamento médio dos tijolos $A$ e $B$ em relação à escória do conversor, é muito semelhante, como esperado pela composição semelhante dos tijolos.
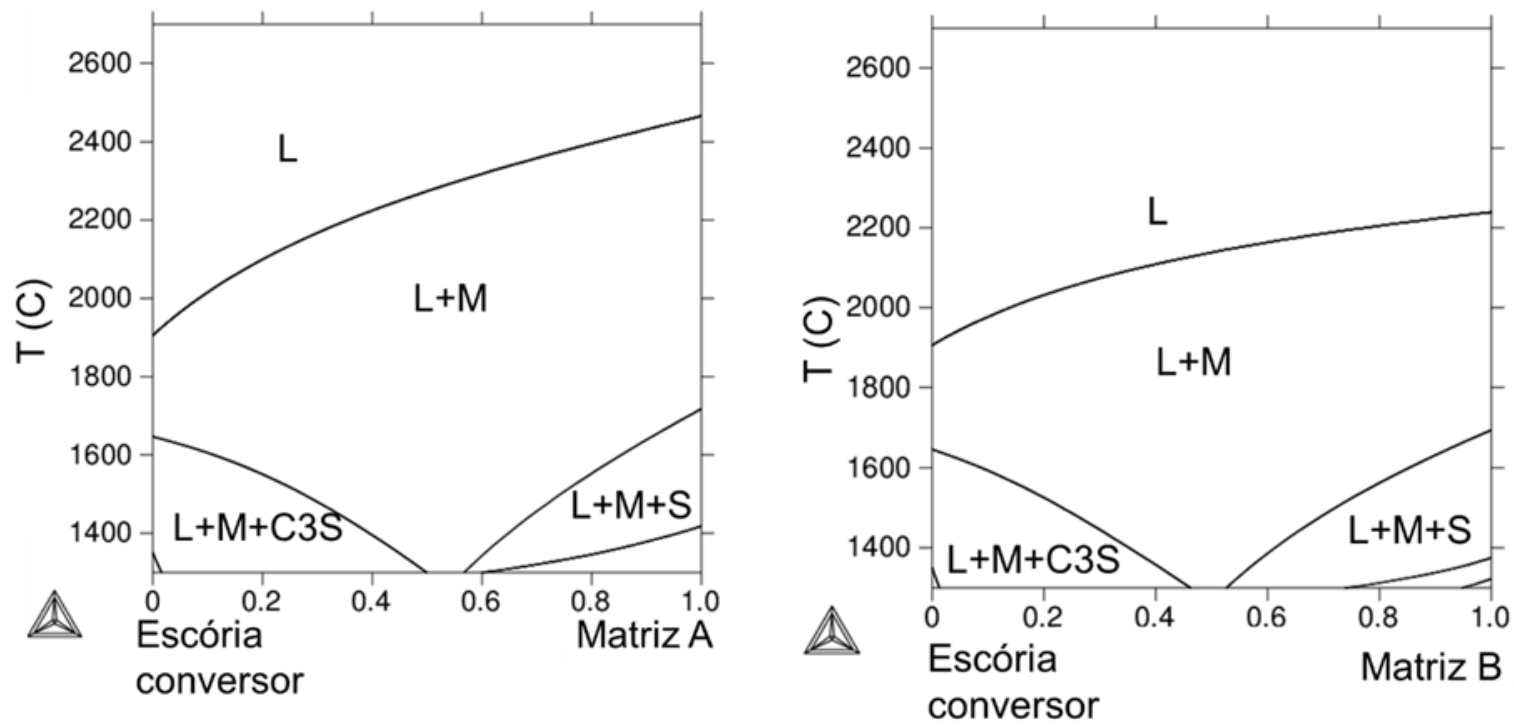

Figura 7 Isopletas entre a escória de conversor e as composições médias dos tijolos A e B. O potencial de oxigênio, nos cálculos, foi ajustado para a predominância do $\mathrm{FeO}$ dentre os óxidos de $\mathrm{Fe}$.

Na Figura 7 observa-se que o comportamento das matrizes dos tijolos $A$ e $B$ em relação à escória do conversor, é semelhante, na faixa de temperaturas relevantes para aciaria. Como isopletas não permitem a aplicação da "regra da alavanca" não é possível estimar a fração de fase líquida presente durante esta interação. Assim, os diagramas de fração de fase a uma temperatura arbitrada para a face quente, apresentados na figura, são úteis para esta avaliação. 

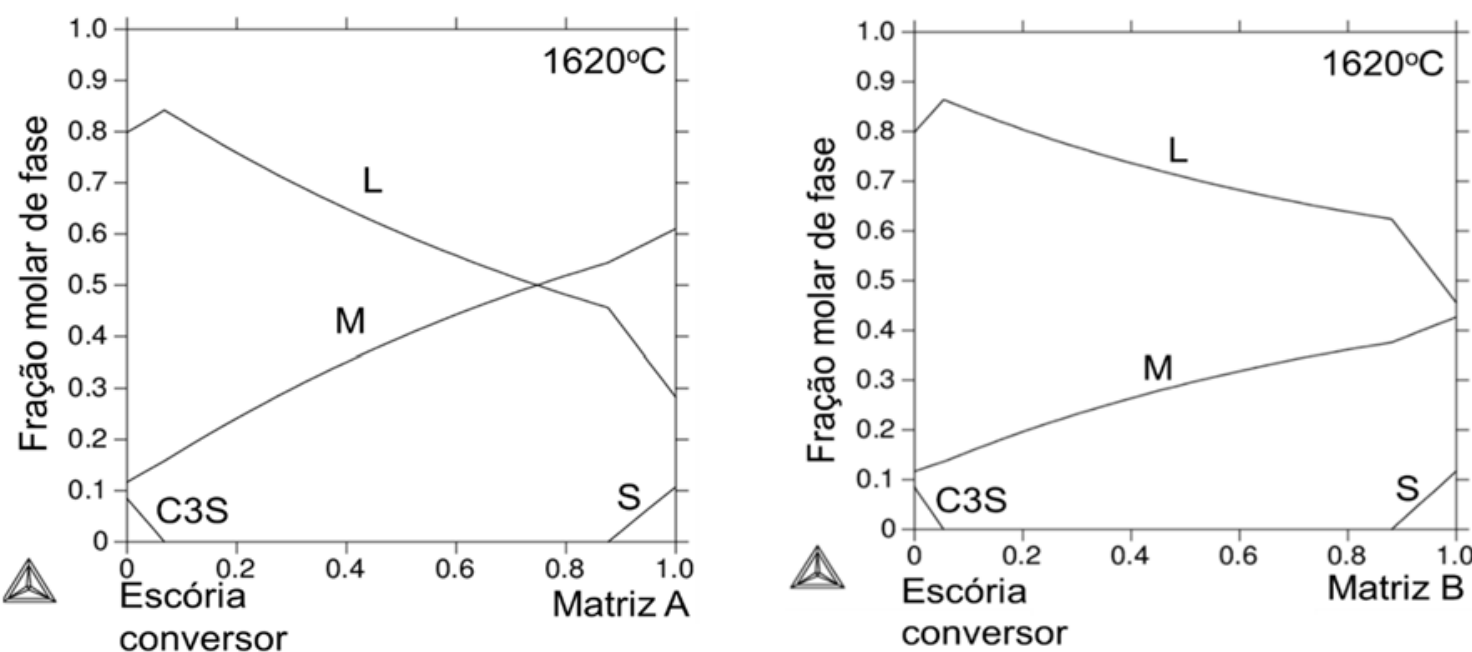

Figura 8 Fração de fases presentes à medida que a fração de escória do conversor e matriz do refratário variam de 0 a 1 na temperatura arbitrária de $1620 \mathrm{C}$.

A Figura 8 indica que a quantidade de líquido formada na interação da matriz do tijolo A com a escória do conversor é menor do que no tijolo $B$, resultando em menor dissolução da fase $\mathrm{MgO}$, em equilíbrio. O mesmo tipo de gráfico pode ser utilizado para avaliar a interação entre escória da EB (aço acalmado) e os dois tijolos (Figura 9).
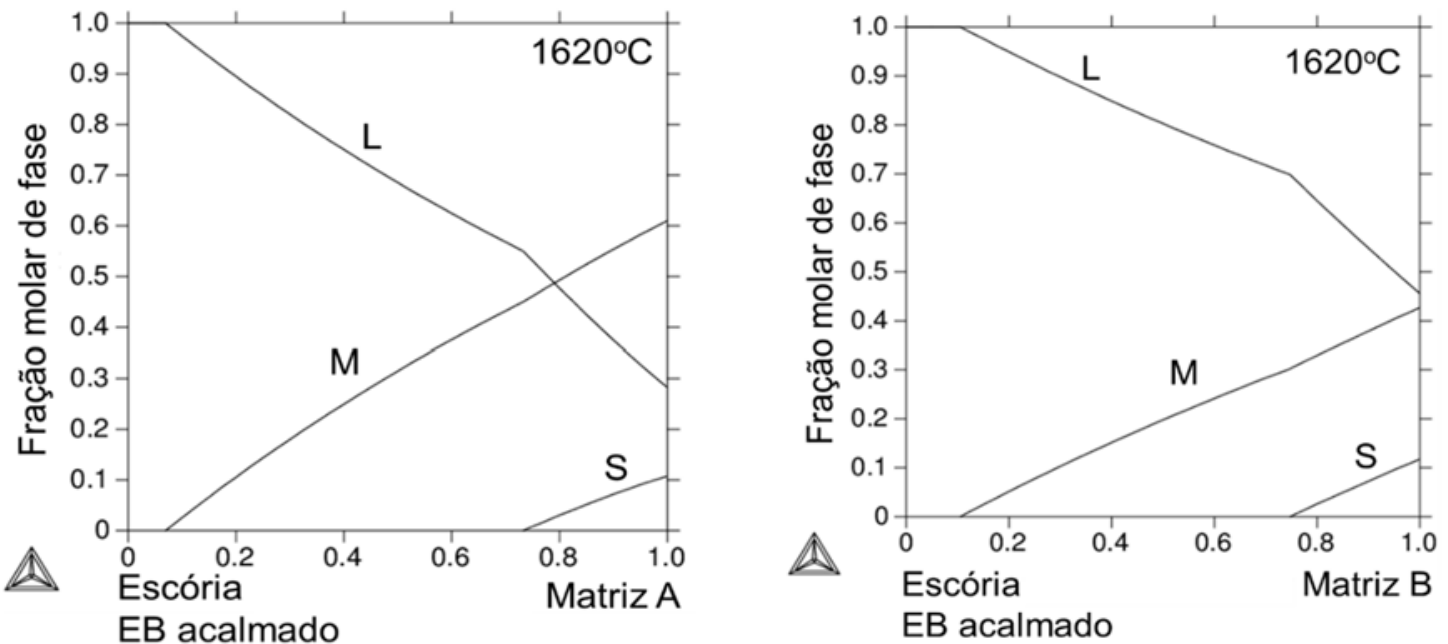

Figura 9 Fração de fases presentes à medida que a fração de escória da EB (aço acalmado) e matriz do refratário variam de 0 a 1 na temperatura arbitrária de $1620 \mathrm{C}$.

A Figura 9 também indica que a quantidade de líquido formada na interação da matriz do tijolo A com a escória da EB (aço acalmando) é menor do que no tijolo B, resultando em menor dissolução da fase $\mathrm{MgO}$, em equilíbrio.

\section{CONCLUSÃO}

As reações entre refratários e escória, na metalurgia de panela dependem da força motriz termodinâmica e de diversos fatores cinéticos. O projeto dos modernos refratários $\mathrm{MgO}-\mathrm{C}$ busca dificultar ao máximo a interação refratário-escória através do uso de grafita, reduzindo molhabilidade, dificultando contato de partículas e reações que possam levar à formação de líquido e favorecendo a formação de uma camada 
densa de $\mathrm{MgO}$ na face de trabalho. Ainda assim, é fundamental conhecer a termodinâmica das reações possíveis entre a escória e o refratário pois esta representará a força motriz para a degradação do refratário. Embora diversos métodos de cálculo termodinâmico tenham sido usados para a previsão desta degradação, no presente trabalho é apresentado um método simples, empregando a termodinâmica computacional, em que a principal variável de estudo é a fração de refratário ou fração da matriz de refratário em uma mistura com a escória a estudar. O uso desta variável permite avaliar um amplo campo de interações possíveis e produzir resultados de interpretação relativamente simples, úteis na avaliação dos refratários. Como a degradação por corrosão envolve tanto a matriz, como as "fases acessórias" presentes nos grãos de magnésia eletrofundida, avaliações mais exatas dependem de conhecimento detalhado da composição destas duas partes do refratário. Além disto, em vista da importância fundamental da cinética na degradação dos refratários, os resultados termodinâmicos assim obtidos são uma primeira informação a ser considerada, não eliminando a necessidade de testes cinéticos ou testes em escala industrial.

\section{Agradecimentos}

ACS agradece a CSN e a Magnesita o apoio e autorização para uso de dados.

\section{REFERÊNCIAS}

1 Trommer, R.M. et al. Identificação e avaliação dos mecanismos de ataque da escó-ria $\mathrm{SiO} 2-\mathrm{CaO}-\mathrm{Al} 2 \mathrm{O} 3-\mathrm{MgO}$ em tijolos refratários MgO-C. Matéria, 2008:13 p. 56-64.

2 Hashemi B, Nemati ZA, Faghihi-Sani MA. Effects of resin and graphite content on density and oxidation behavior of MgO-C refractory bricks, Cer. Inter.2005.

3 Leite, FC, Luz, AP, Pandolfelli, VC. Características e mecanismos de desgaste dos refratários MgO-C usados na linha de escória de panelas de aço. Cerâmica, 2014:60(355) 348-365.

4 Braulio MAL, et al. Variação do tamanho de grão da magnésia: um exemplo da complexidade de cerâmicas refratária. Cerâmica 2010:56(339), 222-227

5 Lee W.E., Zhang G S, Melt corrosion of oxide and oxide-carbon refractories. Int. Mat. Rev. 1999;44(3):77-104.

6 Brosnan, DA. "Corrosion of refractories", In: Refractories Handbook, Schacht CA,ed , Marcel Dekker, NY, 2004.

7 Kasimagwa, I, Brabie V, Jönsson, PG. Slag corrosion of MgO-C refractories during secondary steel refining. Ironmaking \& Steelmaking. 2014 Feb;41(2):121-31.

8 Costa e Silva, A. Apostila Refino dos Aços e Seus Objetivos, 2012, capítulo 6, p. 10, disponível em http://equilibriumtrix.net/, (acessado em 01 de abril de 2016).

9 Lee W.; Argent BB, Zhang S. Complex Equilibria in Refractories Design and Use. Journal of the American Ceramic Society, 2002:85(12) 2911-2918.

10 Lehmann J, Boher M, Soulard H, Gattelier H. Metal/refractory interactions- a thermodynamic approach. In: Proc. of UNITECR 2001. Cancun, MX ALAFAR; 2001.

11 Lehmann J, Boher M, Kaerle MC. An experimental study of the interactions between liquid steel and MgO-based tundish refractories. CIM Bulletin. 1971;90:69-74

12 Watanabe A, Takahashi A, Nakatani, F. Mechanism of Dense Magnesia Layer Formation near the Surface of Magnesia-Carbon Brick .J. Amer. Cer. Soc., 1986: 69(9) C-2134-214.

13 Lee JW, Duh JG. High-temperature MgO-C-Al refractories-metal reactions in highaluminum-content alloy steels. J. Materials Research. 2003;18(8):1950-9.

14 Kasimagwa, I. A study of slag corrosion of oxides and oxide-carbon refractories during steel refining Licenciate Thesis, KTH, Stockholm: 2010 
15 Sundman B, Jansson B, Anderson JO. The Thermo-Calc databank system. CALPHAD. 1985;9:153-90.

16 TCAB, SLAG Database, v3. Stockholm, 2012.

17 ABNT, NBR 6220-2011, Materiais refratários densos conformados - Determinação do volume aparente, densidade de massa aparente, porosidade aparente, absorção e densidade aparente da parte sólida, SP,. 2011.

18 ASTM. E 562-02 Standard Test Method for Determining Volume Fraction by Syste-matic Manual Point Count ASTM E 562-02. W. Conshohocken, PA: ASTM; 2002. 